University of Nebraska - Lincoln

DigitalCommons@University of Nebraska - Lincoln

\title{
IMMUNOCONTRACEPTION IN EASTERN GRAY SQUIRRELS (SCIURUS CAROLINENSIS): MORPHOLOGIC CHANGES IN REPRODUCTIVE ORGANS
}

\author{
Murali Pai \\ North Slope Borough Department of Wildlife Management, ecovetpai@yahoo.com \\ R. Bruner \\ Research Pathology Associates, LLC \\ Donald H. Schlafer \\ Cornell University \\ Greg K. Yarrow \\ Clemson University, gyarrow@clemson.edu \\ C. A. Yoder \\ National Wildlife Research Center, christi.yoder@aphis.usda.gov \\ See next page for additional authors \\ Follow this and additional works at: https://digitalcommons.unl.edu/icwdm_usdanwrc \\ Part of the Life Sciences Commons
}

Pai, Murali; Bruner, R.; Schlafer, Donald H.; Yarrow, Greg K.; Yoder, C. A.; and Miller, Lowell A., "IMMUNOCONTRACEPTION IN EASTERN GRAY SQUIRRELS (SCIURUS CAROLINENSIS): MORPHOLOGIC CHANGES IN REPRODUCTIVE ORGANS" (2011). USDA National Wildlife Research Center - Staff Publications. 1365.

https://digitalcommons.unl.edu/icwdm_usdanwrc/1365

This Article is brought to you for free and open access by the U.S. Department of Agriculture: Animal and Plant Health Inspection Service at DigitalCommons@University of Nebraska - Lincoln. It has been accepted for inclusion in USDA National Wildlife Research Center - Staff Publications by an authorized administrator of DigitalCommons@University of Nebraska - Lincoln. 


\section{Authors}

Murali Pai, R. Bruner, Donald H. Schlafer, Greg K. Yarrow, C. A. Yoder, and Lowell A. Miller 


\title{
IMMUNOCONTRACEPTION IN EASTERN GRAY SQUIRRELS (SCIURUS CAROLINENSIS): MORPHOLOGIC CHANGES IN REPRODUCTIVE ORGANS
}

\author{
Murali Pai, M.V.Sc., Ph.D., R. Bruner, D.V.M., Dipl. A.C.V.P., Donald H. Schlafer, D.V.M., Ph.D., \\ Dipl. A.C.V.P., Greg K. Yarrow, D.F., Christi A. Yoder, Ph.D., and Lowell A. Miller, Ph.D.
}

\begin{abstract}
Eastern gray squirrels (EGS) (Sciurus carolinensis) damage trees through bark stripping or gnawing due to territorial marking or agonistic gnawing behavior in concert with higher densities. This study was conducted to determine the effects of a contraceptive vaccine on EGS and its reproductive organ histology. Freeranging urban EGS were vaccinated with the immunocontraceptive GonaCon ${ }^{\mathrm{TM}}$. All EGS were $\geq 6$ mo of age as determined by a combination of pelage characteristics and body weights. The vaccine was administered by injection at a dosage rate of $0.4 \mathrm{ml}$ containing $400 \mu \mathrm{g}$ of GnRH-mollusk protein conjugate i.m. in the thigh to 33 EGS (17 male [m], 16 female [f]) in trapping session 1 (TS1), 23 (14 m, 9f) in trapping session 2 (TS2), and 11 (8 m, $3 \mathrm{f}$ ) in trapping session 3 (TS3). A sham injection containing $0.4 \mathrm{ml}$ saline-AdjuVac ${ }^{\mathrm{TM}}$ was given as control to 22 EGS (16 m, $6 \mathrm{f})$ in TS1, $20(12 \mathrm{~m}, 8 \mathrm{f})$ in TS2, and $8(4 \mathrm{~m}, 4 \mathrm{f})$ in TS3. In the last trapping session (TS4), 35 EGS (16 treated, 19 control) were killed for necropsy to evaluate histologic changes in testes and ovaries. Treated EGS males had testicular, prostatic, and epididymal atrophy compared with control EGS males. The tubuli seminiferi and prostatic glandular lumen of treated EGS males were atrophic, and the epididymal lumen contained no sperm cells. No histologic changes were observed in treated EGS females; however, females likely were not collected when changes due to GonaCon ${ }^{\mathrm{TM}}$ would have been observed. There were no observable histologic differences in the pituitary gland of treated and control EGS. There were no statistically significant differences in either testosterone or progesterone concentrations between control and treated EGS. Although there were no serious side effects to the vaccine, six EGS developed injection site abscesses. GonaCon ${ }^{\mathrm{TM}}$ may be a potential tool for EGS population control.
\end{abstract}

Key words: Eastern gray squirrels, GonaCon ${ }^{\mathrm{TM}}$, testicular and prostatic atrophy, immunocontraception, population control, Sciurus carolinensis.

\section{INTRODUCTION}

Many species of rodents are overabundant and invasive worldwide. In contrast to their typical existence in rural forests, Eastern gray squirrels (EGS) in urban areas tend to exhibit higher population densities, increased rates of intraspecific aggression, and reduced wariness toward humans. ${ }^{23}$ Damage and death of hardwood trees caused by EGS, through bark stripping and gnawing, is a result of territorial marking or

From the North Slope Borough Department of Wildlife Management, P.O. Box 69, Barrow, Alaska 99723, USA (Pai); Research Pathology Associates, LLC, 220, Pendleton Road, Clemson, South Carolina 29631, USA (Bruner); Cornell University Department of Biomedical Sciences, T6-020 VRT, College of Veterinary Medicine, Tower Road, Ithaca, New York 14853, USA (Schlafer); Clemson University Department of Foresty and Natural Resources, 261, Lehotsky Hall, Clemson, South Carolina 29634, USA (Yarrow); and USDA/ APHIS/WS/National Wildlife Research Center, Fort Collins, 4101 LaPorte Avenue, Fort Collins, Colorado 80521, USA (Yoder, Miller). Correspondence should be directed to Dr. Pai (ecovetpai@yahoo.com). agonistic gnawing behavior in concert with higher densities. ${ }^{9,13}$ Due to the presence of EGS in urban settings, lethal control measures are not always acceptable.

GonaCon $^{\mathrm{TM}} \quad$ (USDA/APHIS/WS/National Wildlife Research Center, Fort Collins, Colorado 80521, USA) is an anti-GnRH vaccine based on a peptide antigen mollusk hemocyanin carrier protein conjugated to GnRH in an oil-based adjuvant (AdjuVac ${ }^{\mathrm{TM}}$ ). ${ }^{19}$ Immunoneutralizaton of $\mathrm{GnRH}$ provides contraception in mammals and has been shown to control estrus in females and sexual aggression in males. ${ }^{17}$ The vaccine has proved to be effective in such species as Norway rats (Rattus norvegicus), California ground squirrels (Spermophilus beecheyi), and cats (Felis catus)..$^{15,18,21}$ No studies have been conducted to date with GonaCon on EGS.

The goal of this work was to evaluate the safety and efficacy of GonaCon in reducing fecundity of free-ranging EGS (Sciurus carolinensis) in urban areas. The study focused on characterizing and quantifying morphologic changes in the reproductive organs of male and female EGS that followed vaccination with GonaCon. 


\section{MATERIALS AND METHODS}

Using a modified box trap design, 317 EGS were captured during four trapping sessions on a 5.66-ha site on the main campus of Clemson University (Clemson, South Carolina, USA). Eastern gray squirrels were handled using a restraint cone and sexed, weighed, ear-tagged, and implanted with a microchip at the nape of the neck on all "original" captures; these were later identified in subsequent captures as "recaptures." Although both control and treated EGS were free ranging in the same study area, EGS were randomly assigned to treatment groups upon capture. No trapping occurred outside this area due to logistical constraints. GonaCon-AdjuVac was administered by injection at a dose of $0.4 \mathrm{ml}$ containing $400 \mu \mathrm{g}$ of GnRH-mollusk protein conjugate intramuscularly in the thigh to 33 EGS (17 male [m], 16 female [f]) in trapping session 1 (TS1 = March-April 2008), 23 (14 m, 9 f) in trapping session 2 (TS2 = July 2008), and 11 (8 $\mathrm{m}, 3 \mathrm{f}$ ) in trapping session 3 (TS3 $=$ November 2008). Control EGS were given a sham injection containing $0.4 \mathrm{ml}$ saline-AdjuVac during the three trapping sessions: 22 EGS $(16 \mathrm{~m}, 6 \mathrm{f})$ in TS1, 20 $(12 \mathrm{~m}, 8 \mathrm{f})$ in TS2, and $8(4 \mathrm{~m}, 4 \mathrm{f})$ in TS3. All EGS were $\geq 6$ mo of age as determined by a combination of pelage characteristics and body weight. ${ }^{5}$ Thirty-three serum samples were collected over three trapping sessions from seven control and seven treated EGS males and testosterone concentrations determined using radioimmunoassay. Thirty serum samples were collected over three trapping sessions from 12 treated and 7 control EGS females and progesterone concentrations determined using radioimmunoassay. ${ }^{6,25}$ In May and June of 2009, 35 EGS were humanely killed by an overdose of halothane anesthesia. Necropsy examinations were performed on all 35 EGS: 18 males ( 8 treated, 10 control) and 17 females ( 8 treated, 9 control). All necropsies were performed within 10 min after EGS were killed. Measurements included body weights, weights of testes and ovaries, examination of injection sites, and documentation of any grossly evident abnormalities. Ovaries and uteri were collected from females and fixed in $10 \%$ neutral buffered formalin. Testes and prostate glands were collected from males and fixed in modified Davidson's fluid. ${ }^{14}$ The pituitary gland was collected from both sexes and fixed in 10\% neutral buffered formalin. Histologic examination was conducted after tissues were embedded in paraffin and stained with H\&E. Prepared histologic slides were interpreted by a veterinary pathologist using an
Table 1. No significant differences in testosterone concentrations $(\mathrm{ng} / \mathrm{ml})$ of treated and control male Eastern gray squirrels over 3 trapping sessions.

\begin{tabular}{lcrcc}
\hline Group & Season & \multicolumn{1}{c}{$n$} & Testosterone $(\mathrm{ng} / \mathrm{ml})$ & SEM \\
\hline Control & 1 & 12 & 0.5 & 0.1 \\
& 2 & 9 & 0.3 & 0.1 \\
Treated & 3 & 1 & 0.4 & 0.2 \\
& 1 & 11 & 0.6 & 0.1 \\
& 2 & 5 & 0.3 & 0.1 \\
& 3 & 6 & 0.4 & 0.1 \\
\hline
\end{tabular}

optical microscope equipped with a camera. Mean wet weights of testes and ovaries, diameter of uterine horns, and length of the reproductive tract were analyzed using a pair-wise $t$-test. Proportions of EGS with testicular, epididymal, and prostatic atrophy were evaluated according to standard norms ${ }^{2,7,16}$ and compared using chisquared analysis. Differences were deemed to be significant at $P<0.05$.

\section{RESULTS}

The mean wet testes weight of treated EGS males was $336 \pm 61.22 \mathrm{mg}$ and 4,010 $\pm 704.64 \mathrm{mg}$ for control males, a highly significant $(\mathrm{t}=5.19$, df $=8.12, P=0.0008)$ reduction in testes weights between treated and control males. In contrast, the mean wet weight of ovaries of control EGS females was $103 \pm 25.96 \mathrm{mg}$ and $98 \pm 8.61 \mathrm{mg}$ for treated EGS females, which were not significantly different from one another $(\mathrm{t}=0.17, \mathrm{df}=9.73, P=$ $0.86)$.

There were no significant differences between testosterone concentrations of treated and control EGS males by the third trapping session (Table 1). There were no significant differences between progesterone concentrations of treated and control EGS females by the third trapping session (Table 2).

Table 2. No significant differences in progesterone concentrations $(\mathrm{ng} / \mathrm{ml})$ of treated and control female Eastern gray squirrels over 3 trapping sessions.

\begin{tabular}{lcrcc}
\hline Group & Session & $n$ & Progesterone $(\mathrm{ng} / \mathrm{ml})$ & SEM \\
\hline Control & 1 & 10 & 1.2 & 0.2 \\
& 2 & 4 & 2.7 & 0.4 \\
Treated & 3 & 4 & 1.3 & 0.4 \\
& 1 & 11 & 1.6 & 0.2 \\
& 2 & 3 & 0.9 & 0.4 \\
& 3 & 1 & 2 & 0.7 \\
\hline
\end{tabular}




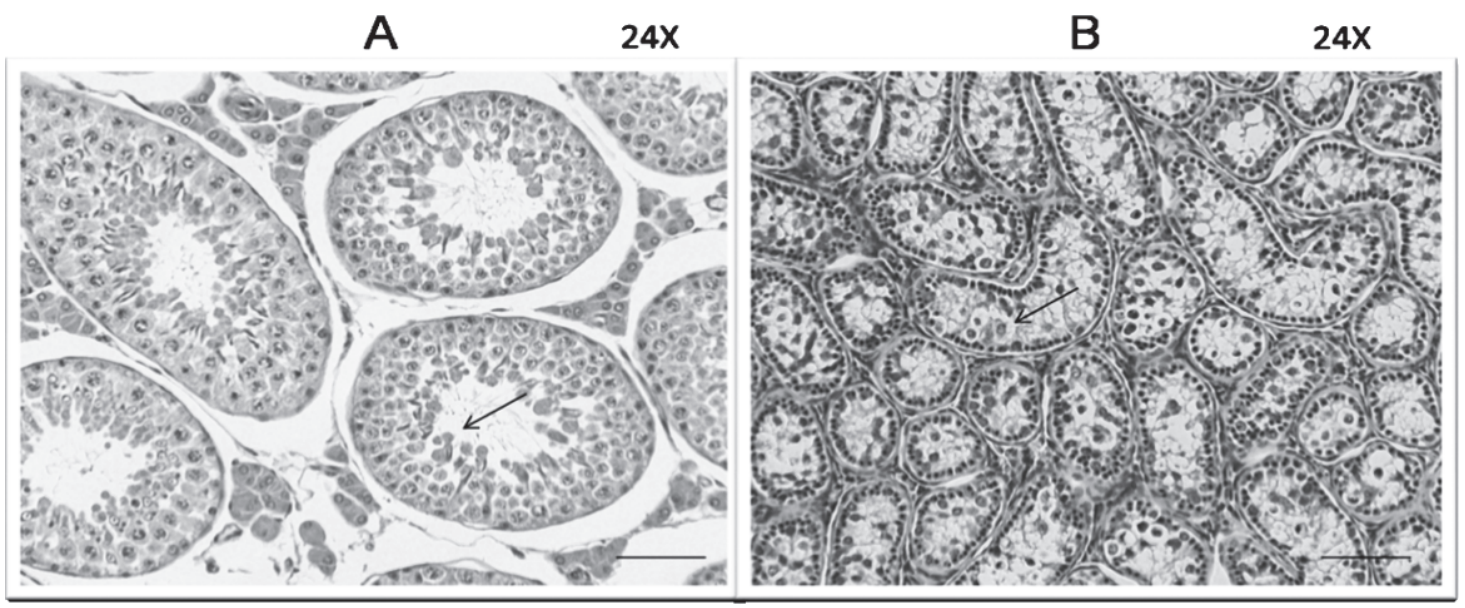

Figure 1. Cross-section of testes of male control (A) and GonaCon-treated (B) Eastern gray squirrels (H\&E, bar $=90 \mathrm{~mm}$ ) indicating atrophy in treated males (arrow indicates germinal epithelium).

The proportion of treated EGS males with atrophic tubuli seminiferi and Leydig cells and vacuolated Sertoli cells was 1.0 compared with 0.0 for control EGS males $\left(\chi^{2}=18.0, \mathrm{df}=1, P=\right.$ 0.0001). Representative cross-sections of testes in control EGS males exhibited densely packed tubuli seminiferi with intact spermatogenesis (Fig. 1A) and a robust population of interstitial cells. In treated EGS males, atrophic tubuli seminiferi (Fig. 1B) containing some degenerating spermatocytes were observed. Interstitial cells were small and more difficult to discern. The diameter of the epididymis was greatly reduced in treated EGS males and, unlike control males, did not have sperm cells in their lumen. The prostatic glandular lumen of treated EGS males was markedly atrophic compared with prostatic tissues from control males (Fig. 2A, B).

In EGS females, there were no significant differences in the diameter of uterine horns (control $=1.8 \pm 0.2 \mathrm{~mm}$ and treated $=1.8 \pm 0.2$ $\mathrm{mm} ; \mathrm{t}=-0.14, \mathrm{df}=10.5, P=0.88)$ or in the length of the tract from the vagina to the ovaries (control $=73 \pm 5.7 \mathrm{~mm}$ and treated $=73 \pm 4.3 \mathrm{~mm} ; \mathrm{t}=0.06$, df $=14.5, P=0.95$ ). Moreover, there were no significant differences in lesion scores for repro-

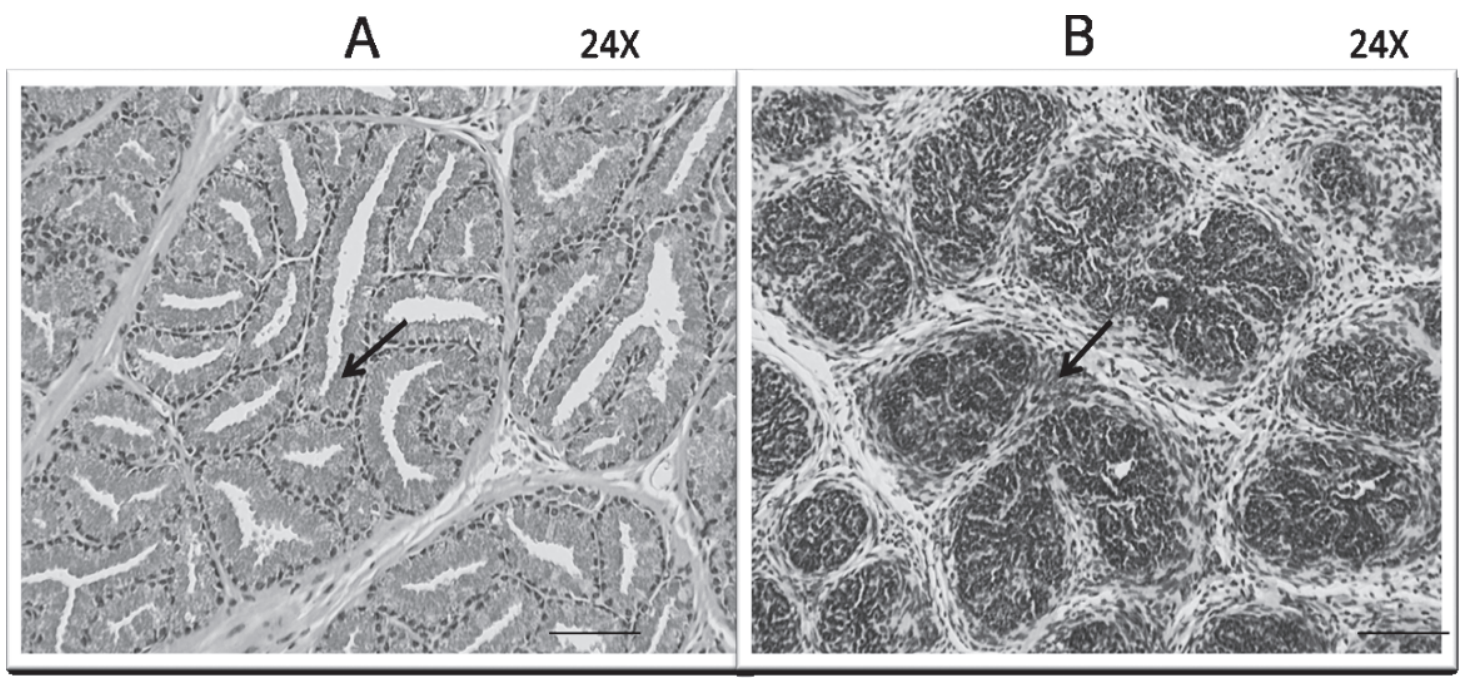

Figure 2. Cross-section of prostate of male control (A) and GonaCon-treated (B) Eastern gray squirrels (H\&E, bar $=90 \mathrm{~mm}$ ) indicating atrophy in treated males (arrow indicates glandular epithelium). 
ductive organs of vaccinated and control females. Histopathology also revealed no observable differences in pituitary tissues between both control and treated male and female EGS.

\section{DISCUSSION}

This study found that vaccination of male EGS with GonaCon produced a dramatic reduction in testes weight $(90 \%)$ and a complete failure of sperm production. Considering the functional outcomes in other species with similar lesions, these findings suggest that GonaCon-treated EGS males were at least temporarily immunocontracepted. ${ }^{3,8,13,15}$ For example, our findings are consistent with those in other animals, such as GonaCon-treated male white-tailed deer, in whom testes size was also reduced as a result of antiGnRH immunocontraception. ${ }^{2,3}$

Male EGS normally undergo a semiannual cycle of testicular recrudescence and regression and occasionally skip entire breeding seasons. ${ }^{11,24,25}$ Although some animals in this study may have been experiencing a cessation of reproduction, there was no evidence of gonadal inactivity in any control males. The extremely reduced testes weights, epididymal diameter, and atrophy of the prostatic glandular lumen in the vaccinated males were absent from the controls. However, no statistically significant difference was found between testosterone concentrations of control and treated EGS males. The small sample size likely did not provide adequate power to detect differences.

There was no statistically significant difference found between progesterone concentrations of control and treated EGS females due to small sample size. It is also plausible that samples were not collected when females were pregnant and therefore no differences were found in progesterone concentration.

No histologic changes were observed in the ovaries or uteri of GonaCon-treated or control EGS females. The most likely explanation for this is that females were not collected when changes due to GonaCon would likely be observable. Breeding generally occurs from May to June, ${ }^{22}$ and histologic samples were collected during this period. However, the largest number of tertiary follicles is observed in pregnant females, with the lowest number being observed in females close to estrous. This is likely due to increased follicular atresia occurring in estrous females and decreased atresia occurring in pregnant females. ${ }^{1}$ Pregnant females also have higher ovarian weights than lactating or anestrous females. ${ }^{1,4}$ Therefore, it seems unlikely that ovarian changes due to GonaCon would be expected to be observed during the collection period. Litters are generally produced from March to April and July to August. ${ }^{12}$ Uterine changes, such as increased size and blood vessels, would only be expected to be observed in pregnant females. ${ }^{19}$ Because no pregnant females were observed in either the control or the treated group from the animals collected, it is not surprising that no significant changes were observed in uterine histology. Juveniles are usually weaned around $7 \mathrm{wk}$; therefore, it is unlikely that histologic changes in mammary tissue would have been observed during the period when animals were collected. ${ }^{10}$

Although changes were observed in males, the male reproductive system develops earlier in the season than the female reproductive system due to the length of spermatogenesis. ${ }^{10}$ Functionally breeding males are usually found almost yearround. ${ }^{9}$ In general, testicular recrudescence occurs from August to October, lasting approximately 2 mo per individual. After this, spermatogenesis occurs as early as December. ${ }^{21}$

There were no perceivable histologic changes in the pituitary glands of male and female EGS that were injected with GonaCon compared with control animals. The pituitary regulates other physiologic processes in EGS as in other mammals, and it is important that these processes are not disrupted or compromised by GonaCon. A study found that active immunization against GnRH in pigs caused damage to cells in the hypothalamus other than those producing GnRH (an action called a bystander effect). ${ }^{20}$

GonaCon use in males may help reduce or alleviate territorial marking and bark stripping, which seems to be a learned behavior in EGS males. ${ }^{9}$ However, male-based contraception is an inadequate management strategy in most cases. Therefore, both male and female squirrels should be treated for population control. Although this study did not address fertility of vaccinated males or females over time in breeding trials, the dramatic alternation in testicular and accessory sex gland morphology is strong evidence that vaccination causes temporary subfertility in EGS males. Additional studies are needed to adequately assess the efficacy of GonaCon in female EGS.

Acknowledgments: Funding for this project was provided, in part, by the Jack H. Berryman Institute, Mississippi State University, Mississippi, USA. Support was also provided by the USDA 
National Wildlife Research Center, Fort Collins, Colorado, USA. We thank the Godley-Snell Research Center, Clemson University, Clemson, South Carolina, USA, for technical support, as well as student volunteers at Clemson University who contributed to data collection.

\section{LITERATURE CITED}

1. Cowles, C. J., R. L. Kirkpatrick, and J. O. Newell. 1977. Ovarian follicular changes in gray squirrels as affected by season, age, and reproductive state. J. Mammal. 58: 67-73.

2. Creasy, D. M. 2003. Evaluation of testicular toxicology: a synopsis and discussion of the recommendations proposed by the Society of Toxicologic Pathology. Birth Defects Research Part B. Dev. Reprod. Toxicol. 68: 408-415.

3. Curtis, P. D., M. E. Richmond, L. A. Miller, and F. W. Quimby. 2008. Physiological effects of gonadotropin-releasing hormone immunocontraception on white-tailed deer. Hum. Wildl. Conflicts 2: 68-79.

4. Deanesley, R., and A. S. Parkes. 1933. The reproductive processes of certain mammals. Part IV. The oestrus cycle of the gray squirrel (Sciurus carolinensis). Philos. Trans. R. Soc. Lond. B Biol. Sci. 22: 47-96.

5. Dimmick, R. W., and M. R. Pelton. 1996. Criteria of sex and age. In: T. A. Bookhout (ed.). Research and Management Techniques for Wildlife and Habitats, 5th ed. Allen Press Inc., Lawrence, Kansas. Pp. 169-214.

6. Holekamp, K. E., and F. Talamantes. 1991. Seasonal variation in circulating testosterone and oestrogens of wild-caught California ground squirrels (Spermophilus beecheyi). J. Reprod. Fert. 93: 414-425.

7. Huang, J.-Y., J.-W. Liao, Y.-C. Liu, S.-Y. Lu, C.-P. Chou, W.-H. Chan, S.-U. Chen, and T.-H. Ueng. 2008. Motorcycle exhaust induces reproductive toxicity and testicular interleukin-6 in male rats. Toxicol. Sci. 103: 137-148.

8. Jain, G. C., H. Pareek, S. Sharma, M. Bhardwaj, and B. S. Khajja. 2007. Reproductive toxicity of vanadyl sulphate in male rats. J. Health Sci. 53: 137141.

9. Kenward, R. E., and T. Parish. 1986. Barkstripping by grey squirrels (Sciurus carolinensis). J. Zool. 210: 473-481.

10. Killian, G., D. Wagner, and L. A. Miller. 2006. Observation on the use of the GnRH vaccine GonaCon in male white-tailed deer. Proc. Wildl. Damage Manage. Conf. 11: 256-263.

11. Kirkpatrick, C. M., and R. A. Hoffman. 1960. Ages and reproductive cycles in a male gray squirrel population. J. Wildl. Manage. 24: 218-221.
12. Koprowski, J. L. 1994. Sciurus carolinensis. Mammalian Species 480: 1-9.

13. Koprowski, J. L. 2005. The response of tree squirrels to fragmentation: a review and synthesis. Anim. Conserv. 8: 369-376.

14. Latendresse, J. R., A. R. Warbrittion, H. Jonassen, and D. M. Craig. 2002. Fixation of testes and eyes using a modified Davidson's fluid: comparison with Bouin's fluid and conventional Davidson's fluid. Toxicol. Pathol. 30: 524-533.

15. Levy, J. K., L. A. Miller, P. C. Crawford, J. W. Ritchey, M. K. Ross, and K. A. Fagerstone. 2004. $\mathrm{GnRH}$ immunocontraception of male cats. Theriogenology 62: 1116-1130.

16. Mali, P. C., A. S. Ansari, and M. Chaturvedi. 2002. Antifertility effect of chronically administered Martynia annua root extract on male rats. J. Ethnopharmacol. 82: 61-67.

17. Meeusen, E. N. T., J. Walker, A. Peters, P. Pastoret, and G. Jungerson. 2007. Current status of veterinary vaccines. Clin. Microbiol. Rev. 20: 489-510.

18. Miller, L. A., B. E. Johns, D. J. Elias, and K. A. Crane. 1997. Comparative efficacy of two immunocontraceptive vaccines. Vaccine 15: 1858-1862.

19. Miller, L. A., J. Rhyan, and G. Killian. 2004. GonaCon a versatile GnRH contraceptive for a large variety of pest animal problems. Proc. Vertebr. Pest Conf. 21: 269-273.

20. Molenaar, C. J., C. Lugard-Kok, R. H. Meloen, R. B. Oouk, J. de Koning, and C. J. G. Wensing. 1993. Lesions in the hypothalamus after active immunization against GnRH in the pig. J. Neuroimmunol. 48: 1-12.

21. Nash, P. B., D. K. James, L. T. Hui, and L. A. Miller. 2004. Fertility control of California ground squirrels using GnRH immunocontraception. Proc. Vertebr. Pest Conf. 21: 274-278.

22. Nixon, C. M., and M. W. McClain. 1975. Breeding seasons and fecundity of female gray squirrels in Ohio. J. Wildl. Manage. 39: 426-438.

23. Parker, T. S., and C. H. Nilon. 2008. Gray squirrel density, habitat suitability, and behavior in urban parks. Urban Ecosyst. 11: 243-255.

24. Webley, G. E., and E. Johnson. 1983. Reproductive physiology of the grey squirrel (Sciurus carolinensis). Mammal. Rev. 13: 149-154.

25. Webley, G. E., G. S. Pope, and E. Johnson. 1985. Seasonal changes in the testes and accessory reproductive organs and seasonal and circadian changes in plasma testosterone concentrations of the male grey squirrel (Sciurus carolinensis). Gen. Comp. Endocrinol. 59: 15-23.

Received for publication 7 October 2010 